\title{
TRIBES OF USERS AND SYSTEMS DEVELOPERS
}

\author{
Sharon Dingley(1), Hanifa Shah (2) and Paul Golder (3)
}

(1) School of Computing, University of Central England, Perry Barr, Birmingham, B42 2SU, UK. Email: sharon.dingley@uce.ac.uk

(2) School of Computing, Staffordshire University,

Beaconside, Stafford, Uk. Email: h.shah@soc.staffs.ac.uk

(3) Department of Computer Science and Applied Mathematics,

Aston University, Aston, Birmingham, UK. Email: Paul.golder@aston.ac.uk

\begin{abstract}
Effective communication is essential for information systems development crossing functional, organisational and national boundaries. As organisations attempt to overcome cultural barriers to communication across the world, communication with colleagues across the corridor remains problematic; cultural barriers between departments remain unchallenged. This paper introduces the concepts of 'culture' and 'tribe' into the discussion of the relationship between business users and information systems developers. Previous research has focused on identifying specific barriers to user-systems developer communication and on ways of eliminating these barriers. In contrast, this paper suggests that much can be learnt through the recognition of cultural differences inherent to the differing roles of user and systems developer. Maintenance of cultural identity is essential to the individual if he/she is to function effectively as a member of his/her tribe, whether it is the 'tribe' of developers or the 'tribe' of users. Communication problems within the systems development process may be addressed by a mutual understanding of cultural differences between the 'tribes' of users and systems developers. This degree of understanding cannot be achieved by attempting to change, persuade or convert the other tribe. The problems of user-systems developer communication need to be addressed through effective communication which acknowledges the differing cultures.
\end{abstract}

\section{INTRODUCTION}

The global marketplace provides cultural challenges to corporate competition and alliance. It is recognised that cultural differences affect all business functions and strategies are being developed to address these differences. Information systems and information systems development cross functional, organisational and national boundaries. Recent studies (Tan \& Gable, 1997; Hunter \& Beck, 1996) have investigated the international cross-cultural impact of information systems development. However, as organisations attempt to overcome cultural barriers to international communication, cultural barriers to internal communication remain unchallenged.

Effective communication between business users and systems development staff is essential for the development of information systems which satisfy business needs. Despite much investigation in this area, the seemingly insurmountable division imposed by 'invisible' walls between 'them' and 'us' proves to be stronger than physical departmental walls.

This paper presents a cultural analysis of the communication barriers between the information systems and business functions during information systems development. It is proposed that communication problems can be explained in term of inherent cultural differences between departmental communities and that an understanding and appreciation of cultural behaviour can help improve interdepartmental relations.

Becher (1989) describes academic disciplines as tribes with their own territory (building on campus), language (specialist terms) and artifacts (e.g. computer manuals). A key problem of interdisciplinary inquiry is the interpretation of terminology specific to the native discipline. However, Ackerman (1965) suggests that interdisciplinary work does not require encyclopaedic knowledge of the foreign area. He rejects the view that a complete understanding of terms, as used by experts in a discipline, is a necessary pre-requisite, proposing that an elementary introduction to principles in a discipline can stimulate invention in another. It is this view which provides the basis for this paper. This paper is written from an information systems perspective and it recognises that a complete understanding of terms used in other academic disciplines is not attainable. The paper provides an elementary introduction to the principles of cultural analysis to stimulate discussion concerning their application and relevance to information systems development.

The following section briefly outlines previous investigations of the user-systems developer relationship. The international cross-cultural impact of information system development is then reviewed, introducing levels of cultural analysis. A cross-cultural analysis of communication barriers between users and systems developers is presented. The paper concludes by considering the practical implications of the concepts discussed.

\section{PREVIOUS INVESTIGATION OF THE USER-SYSTEMS DEVELOPER RELATIONSHIP}

The importance of effective user-systems developer communication during the analysis and design of information systems has been widely recognised. Problems resulting from poor communication and common theories for these problems arising are outlined in Shah et al.(1994). Various aspects of the user-developer relationship which have been investigated by information systems researchers are summarised by Joshi (1992). Different approaches to analysing this relationship have included:

1. Investigating user involvement in information systems development and the affect of this on the resultant information systems (Baroudi et al., 1986). 
2. Examining the user-systems developer relationship in terms of their relative power (Markus \& BjornAnderson, 1987; Saunders \& Scamell, 1986; Lucas, 1984; Oliver \& Langford, 1984).

3. Exploring conflict in this relationship (Robey \& Farrow, 1982).

4. Employing a communications perspective to examine the interaction between users and systems developers (Bostrom, 1989; Guinan \& Bostrom, 1986; Valusek \& Fryback, 1985; Martin \& Fuerst, 1984).

5. Exploration of users' lack of understanding of computer systems and illogical problem solving approaches (Kaiser \& King, 1982).

6. Examining analysts' technical nature and their lack of appreciation of managerial realities (Werner, 1979).

7. Examining analysts' techno-economic orientation rather than organisational-behavioural orientation (Kumar \& Welke, 1984).

8. Exploring differences in perception (Gingras \& Mclean, 1982) and personality (Kaiser \& Bostrom, 1982; Benbasat et al., 1980).

Although the nature of information systems, the development of information systems and the roles of user and developer have changed, Rourke \& Elliot (1996) report that problems between users and developers still prevent the full business benefits of information systems and information technology being derived. As information systems have evolved from automation to business process redesign, the autonomy of business units has been threatened. This has led to the development of approaches to examine the wider context of information systems (Cavaye \& Christiansen, 1996).

Rourke \& Elliot (1996) identify a number of strategies to resolve or manage differences between users and systems developers. These include education and training of users, the appointment of hybrid managers, outsourcing IT facilities, decentralising IT to users and end user involvement in the development process. However, Kaulio \& Karlsson (1998) focus on user orientation rather than user involvement; user orientation emphasises a positive attitude to users and their contribution to information systems development.

Joshi (1992) identifies a number of 'persuasion' strategies relevant to user-systems developer interaction. These include:

1. Friendliness - attempting to make a favourable impression by being pleasant and congenial, so that the target person will be more likely to do what is requested.

2. Bargaining - involving offers to exchange some benefits or favours based upon social norms of obligation and reciprocity.

3. Reason-attempting to convince others through the use of facts and logical argument.

4. Assertiveness - attempting to influence others by means of forceful manner.

5. Higher Authority - involving the threat of appeal to higher authority or reference to directives from a higher authority.

6. Coalition - mobilising other people in the organisation to assist in persuading the target person.

Underlying these strategies is the basic assumption that a particular strategy must be applied to user-systems developer communication and that the communication process can be improved by the identification of the most appropriate strategy. This view can be enhanced by an understanding of the inherent cultural differences of the two roles. This paper proposes that a cultural analysis of communication barriers can improve the effectiveness of usersystems developer interaction, adopting Kaulio \& Karlsson's (1998) focus of user orientation.

\section{CROSS-CULTURAL INFORMATION SYSTEMS DEVELOPMENT}

Culture can be observed at many different levels, for example, national culture, regional culture, culture of a particular generation, social culture and corporate culture (Hofstede, 1991); at times, these levels of cultural values may conflict. Differences in national and corporate culture are illustrated in a case study (Parkinson, 1993) which investigates the issues which arise when two work groups from different companies and different countries work together on a single project. One group was from a large multinational company based in the United Kingdom, the other group was from a small software house in the United States of America.

Differences in national culture were found to place a significant strain on communication between the two groups. Although both groups spoke the same language (English), communication problems arose because of preconceived ideas held by the groups. The English widely perceive Americans to be brash, over-zealous people and Americans often perceive the English to be 'stuck up' and old fashioned. These cultural stereotypes imposed communication barriers between the groups. Team members had to carefully phrase communication to ensure that the other work group would not be insulted or offended. This is comparable with the user-developer relationship; although both groups appear to 'speak' the same language, preconceptions hinder effective communication.

Similar findings are reported in a study of two work groups in Germany and the United States of America (Meyer, 1993) which documents differing characteristics of conversational style between the German and American work groups. The abrupt, blunt conversational style of the Germans, appeared to be rude and impolite to the American group. In contrast, the informal American style of conversation for establishing social relationships was seen as superficial by the German group. 
In Parkinson's study (1993), corporate cultures differed in a number of ways which affected the views and opinions of the employees. Firstly, the two organisations varied significantly in size; the large organisation shielded employees from external difficulties, such as market forces, to a large extent but in contrast, employees in the smaller organisation were much more exposed to the impact of external factors. This resulted in additional pressures on the team members which affected, for example, the cognitive views of a situation.

Secondly, corporate goals differed; the larger organisation had established quantified strategic goals to improve product quality over the next decade. This clashed with the much shorter term objectives of the smaller organisation which were to expand rapidly and become financially more stable. Such goal differences place strain on the intergroup relationship and as time progresses, such differences can cause the groups to diverge or converge, depending on the current strategies of the groups involved. If the dependency relationship is high then both companies will strive to ensure the intergroup relationship is maintained, conversely, if the intergroup dependency is low then it must be accepted that the relationship will inevitably be under constant strain.

National culture and corporate culture, illustrated in these two case studies, have been examined in the context of cross-cultural joint ventures in the strategic management literature. For example, Barkema et al. (1996) provide evidence to demonstrate that cross-cultural joint ventures are most susceptible to cultural distance than wholly owned subsidiaries because national and corporate culture form a 'double-layered' acculturation. Park \& Ungson (1997) investigate the popular belief that cross-cultural joint ventures are unstable which is based on the premise that the ownership of similar cultural values reduces misunderstanding. They examined 186 joint ventures in the electronics industry and revealed no evidence to support the claim that joint ventures were more likely to dissolve between culturally distant countries. In addition, in contrast to Parkinson's study (1993), similarity of scope, size and age of organisations did not improve the 'fit' of the venture. Park \& Ungson (1997) conclude that the suitability of joint ventures may depend on the participants ability to understand cultural differences.

As cultural differences can severely impede intergroup working, they need to be effectively addressed. The intergroup relationship can be improved if each group understands the culture, thought process and environment of the other. This will enable both groups to appreciate the intergroup relationship so that cultural sensitivities are considered. One way of overcoming this situation would be to use a video camera to record team building exercises which could then be viewed by the other group. In a previous study (Dingley, 1996) video material was used in the preparation for an interview between a British, female, information systems researcher and the American, male, 1993 World Individual Motorcycle Speedway Champion. The purpose of the interview was to review the information and information systems requirements of the sport. Videos of the rider at work at the stadium, being interviewed by journalists and participating in working parties to improve the sport were reviewed. The videos provided an appreciation of the champion's environment, pressures and conversational style which contributed to the preparation of the interview. For example, it was noted that the rider refused to talk of problems or discuss mistakes, speaking only of opportunities. Rather than discussing information systems solutions, the interview was therefore framed by opportunities to improve the provision of information. The videos helped the researcher to learn aspects of the national and 'organisational' culture in preparation for the interview.

Team building activities could be extended to the user-systems developer relationship, if for example, analysts met their prospective users outside the office environment, perhaps they would accept them as people first and users second. This may help to remove the preconceived barriers erected by contextual stereotyping.

Hofstede (1991) recognises that one reason why solutions do not work or cannot be implemented in organisations is because differences in thinking have been ignored. Hofstede suggests that understanding differences in thinking is at least as important as understanding technical factors. A range of tools with which to identify and understand cultural differences are included in Berger (1996). The members of the project teams in the case studies (Parkinson, 1993; Meyer, 1993) were entering each others communities and problems of intergroup communication were caused by a number of cultural differences between the two groups. Differences in the use of language, goals, cognitive views, frames of reference and organisational pressures all contributed to the communication difficulties experienced. We suggest that similar issues arise when two work groups from the same company and in the same country work together on a single project.

\section{CULTURAL ANALYSIS OF USERS AND SYSTEMS DEVELOPMENT GROUPS}

Culture is a holistic principle (Leach, 1965) which is learned and shared by members of an environment (Bird, 1979), providing a guide to acceptable behaviour (Smith, 1990). A person can be examined at three levels of abstraction (Wallerstein, 1990; Hofstede, 1991):

1. Universal inherited characteristics of human nature.

2. Sets of learned characteristics that define a person as a member of a group.

3. The person's idiosyncratic characteristics.

It is the second level of learned characteristics that Wallerstein (1990) labels traits, behaviours, values and beliefs that are neither universal nor idiosyncratic but cultural.

The term 'culture' denotes the 'way of life' of a group of people (Johnson, 1979). This suggests that groups have culture, implying that it is only possible to speak of cultures and not just of culture (Smith, 1990). An individual is a 
member of many groups which each has its specific 'culture'. A person therefore participates in many cultures (Wallerstein, 1990).

A group is more than a collection of individual behaviours; interpersonal interaction and mutual influence; the objective of the group unites members (Zander, 1977) fulfilling the basic human need to belong. Individuals relate to a 'we group' as opposed to 'them', that is, those people who are excluded from the 'we group' (Hofstede, 1991) as a source of identity and protection (Segall et al., 1990). Wallerstein (1990) proposes that culture summarises the distinction between groups, representing what is shared within the group that excludes those outside the group. Leach (1965) observes that all social systems are necessarily subdivided into mutually exclusive segments, which may be actively hostile.

Nanda (1991) defines a tribe as a 'culturally distinct population'; members of the tribe think of themselves as being part of the 'same people'. Members recognise a relationship with other members of the tribe based on ethnic origin, language or pattern of interaction (Pfeiffer, 1977). We suggest that the concept of a tribe can be aptly applied to a group of business users and systems developers. Table 1 applies tribal characteristics to organisational departments.

\begin{tabular}{|c|c|}
\hline A tribe: & A group of employees in a department: \\
\hline Possesses culture. & $\begin{array}{l}\text { Possesses a distinct culture which may have } \\
\text { differing values and beliefs compared with other } \\
\text { departments or that of the organisation as a whole. }\end{array}$ \\
\hline Retains self-awareness. & $\begin{array}{l}\text { Retains a self-awareness of their existence and } \\
\text { purpose. Each member identifies with the group. }\end{array}$ \\
\hline Maintains a sense of boundaries. & $\begin{array}{l}\text { Is aware of the boundaries which separate the group } \\
\text { from the other areas of the organisation - that which } \\
\text { separates 'us' from 'them'. }\end{array}$ \\
\hline $\begin{array}{l}\text { Enforces shared pattern of socialisation to reinforce } \\
\text { values. }\end{array}$ & $\begin{array}{l}\text { Engages in social relationships within the group } \\
\text { which encourage adherence to group values, } \\
\text { necessary to sustain membership. }\end{array}$ \\
\hline Consists of a complex social structure. & $\begin{array}{l}\text { Adopts a complex social structure based on } \\
\text { management hierarchy, subareas, project teams and } \\
\text { seating plans. }\end{array}$ \\
\hline Shares problems. & Shares departmental problems. \\
\hline Engages in rituals for coming together. & $\begin{array}{l}\text { Attends departmental meetings and team briefings } \\
\text { which are rituals to bring the members together. }\end{array}$ \\
\hline $\begin{array}{l}\text { Establishes traditions which sustain cohesive } \\
\text { relationships. }\end{array}$ & $\begin{array}{l}\text { Establishes traditions such as the manner in which } \\
\text { birthdays are celebrated and the 'office Christmas } \\
\text { party' to sustain cohesive relationships. }\end{array}$ \\
\hline $\begin{array}{l}\text { Influences politics closely involved with the rest of } \\
\text { the social organisation. }\end{array}$ & Is influenced by organisational politics. \\
\hline Settles disputes by the next higher order. & $\begin{array}{l}\text { Settles disputes by the next higher order, such as the } \\
\text { next level of management. }\end{array}$ \\
\hline
\end{tabular}

\section{A tribe:}

May operate local units independently. A tribe may be divided into smaller segments such as villages and regional groups which may be further divided into clans and households.

Unites in response to external conditions such as the threat of attack or the opportunity to attack others.

Depends upon informal means for controlling deviant behaviour and settling conflicts. Adopts a common language.

Shares a common goal and distinct practices. A group. of employees in a department: May operate local units independently, for example, a sales team may be divided into regions which operate independently.

Unite in response to external conditions such as the threat of perceived attack by the information systems department.

Depends upon peer pressure to control deviant behaviour.

Possess territory and will actively defend it against intruders.

Adopts a common language of technical terms, codes and abbreviations.

Shares the common goal of the department.

Possesses territory in terms of the boundaries of the department or team within the department.

Table 1: Application of Tribal Characteristics to Organisational Departments

Markarian (1977) defines three points of view which a culturological frame of reference needs to consider. These are the: 
1. Subjects of the activity.

2. Fields of activity, showing the object and goals of the human activity.

3. Mode of activity, describing how the human activity is implemented.

In information systems development, attention has been focused on the field and mode of activity (the 'what' and the 'how'). Denison et al. (1996) propose a three domain model to measure the effectiveness of cross-functional teams which also focuses on the fields and modes of activity. In contrast, the following sections focus on the subjects of the activity and how this focus can improve communication in information systems development.

Table 1 demonstrates that as tribes, users and systems developers have distinct cultures. The richness of culture is reflected in the range of elements that have been identified to explore it. For example, Hofstede (1991, 1998) identifies symbols, heroes, rituals and at the deepest level, values as manifestations of culture; Johnson (1992) proposes a cultural web as a device for undertaking a cultural audit of an organisation which examines: symbols, power structures, organisational structures, controls, rituals and stories. Figure 1 identifies manifestations of culture which affect communication in information systems development. Each of the cultural communication barriers identified in figure 1 are discussed, starting with the most external barrier.

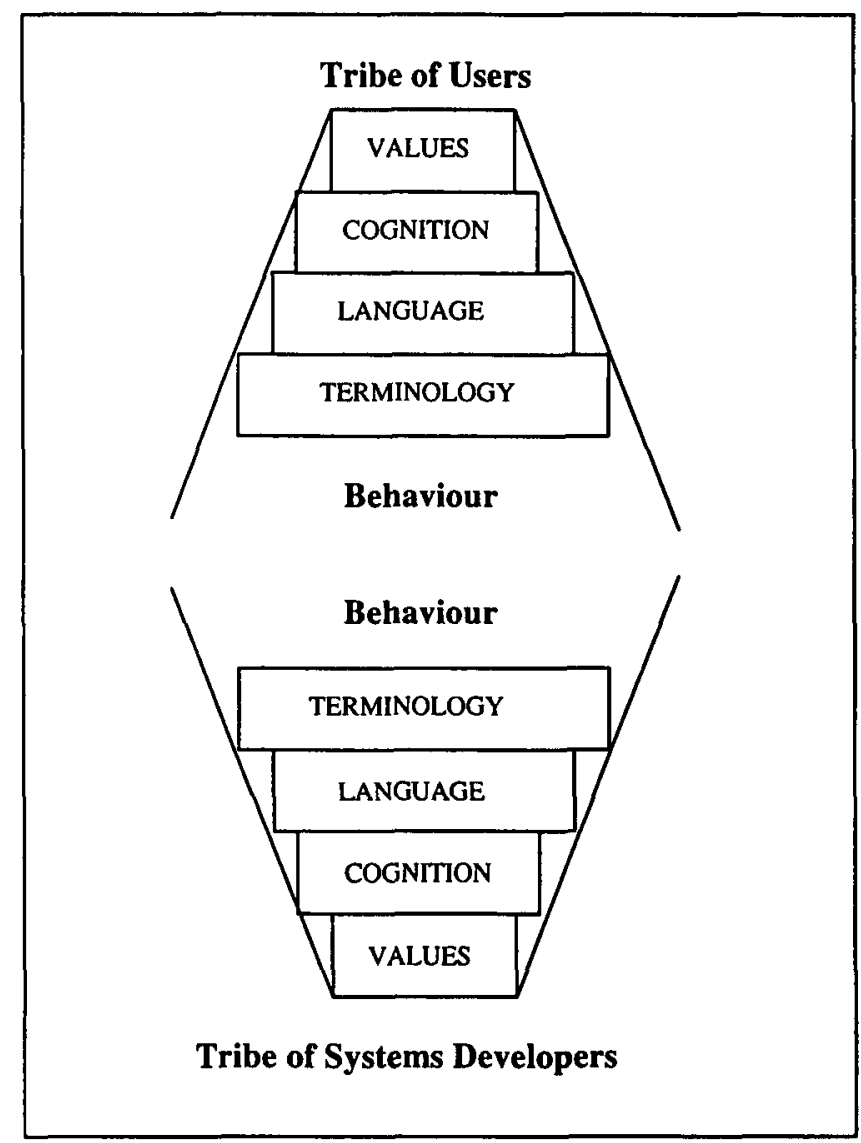

Figure 1: Cultural Communication Barriers in Information Systems Development

\section{Terminology}

Every area of human activity has its own specialist terminology; the computer industry is no exception. Language is an element of culture which assists in maintaining the differentiation between cultural units. Levin (1965) reports that specialist language makes communication difficult even between specialists in different branches of the same field.

The increasing familiarity of computers is perhaps accompanied by the wider acceptance of computer terminology beyond the specialist area. Anderson (1993) suggests that if this were true, there would be a convergence of users' jargon with information systems developers' jargon. Anderson examined professional publications from these different groups for their use of each others jargon and reports a movement of each community away from its own jargon, but not towards the other's. This implies the possible existence of an emerging common jargon, a public language for communication between tribes.

Although computer specialists should refrain from using jargon during communication with business departments, the problem is not limited to computing. Engineering, finance, personnel and sales departments all use specialist terminology which is not widely acknowledged outside the particular area of expertise. All departments must 
recognise that the language they use may not be understood outside their department and such terms should be explained or avoided.

Use of specialist terminology is a barrier to effective communication but an inherent aspect of cultural foundation. The adoption of specialist language within a community fulfils part of the human need to belong but also forms a barrier to exclude others from the group.

\section{Language}

The relationship between language and culture is most clearly shown in the vocabulary of a language which reflects the cultural emphasis and the ways in which the culture categorises its environment (Nanda, 1991). Different communities and individuals within the communities may attribute different meanings to words. Shekelton (1991) recognises that words help us to position ourselves to interact in the world and that although words are not the most accurate tool with which to analyse reality, they are only challenged when a problem of communication arises.

Misunderstandings are a natural occurrence in daily life, however, the implications are more serious when these ambiguities occur during specification of the business requirements which a computer system is required to satisfy. Meaningful communication is dependent upon the prior existence of an agreed set of semantic and syntactic rules which the recipient must use in order to interpret the communication received (defined by the Helsinki principle, Crockett et al., 1991).

Models in information systems development attempt to overcome the ambiguity of natural language. However, Mittermeir et al. (1982) point out that although notation is an important element for efficient communication, both the communicator and the recipient must understand the notation used. Proponents of systems development models hold the view that the notation adopted is intuitive, requiring little explanation. For example, Avison et al. (1992) report of a particular commercial situation where data flow diagrams were considered to form an appropriate basis for user communication. However, for effective communication to take place, the basic concepts behind the notation must first be understood.

When entering another community, it is necessary to consider the use of language from a different point of view. Shekelton (1991) suggests that we should be more cautious of our use of words, considering the possible interpretation which may be applied to the words used.

\section{Cognition}

Cognition may be defined as the way in which humans perceive, understand and organise their response to the environment (Nanda, 1991). Leach (1965) proposes that to understand the relationship between a society and its environment it is necessary to understand the verbal categories which explain how the society organises its environment. Hofstede (1991) states that words are the vehicles of cultural transfer as the categories of words available in the cultural language limit the cognitive visions. The cultural background of a person therefore frames their perception of the world (Leach, 1976). The environment is meaningless if the code which gives it order is not known, for example, a farmer may be 'lost' in a city because a different code is needed to interact with the city culture.

Reality is infinite; individuals view reality through a 'cognitive filter' developed through the cultural values and 'norms' of the adopted community. It is necessary to be conscious of the fact that everyone may have a different, valid view of the world.

Taggart (1982) and Oliver \& Hall (1984) suggest that the barrier between users and systems developers results from a fundamental difference in thinking. They present empirical evidence to support the proposal that systems developers convey objective, reductionist views which are opposed to the subjective, holistic views of the user environment. A systems developer enters a community with the aim of ascertaining an objective view of the situation. Hirschheim \& Neumann (1988) suggest that systems developers are portrayed as being fascinated with the technical aspects of systems and that the culture of systems developers inculcates a belief in their mission to civilise organisations. The members of the community entered have a subjective view of their environment and consider the holistic impact of changes, they are only interested in technology to the extent of its impact on their work.

Mittermeir et al. (1982) describe this distinction between views as users and systems developers holding different frames of reference. The users perceive a holistic system to adopt in the environment in which they are submerged while analysts decompose the system into objects, data, processes, volumes and time constraints.

\section{Values}

Weinberg (1971) suggests there are personality differences between computer and non-computer specialists. This is further supported by Cronan (1984) who lists different areas in which business users and systems developers feel more strongly. However, Ferratt \& Short (1988) conclude that there are no specific differences, other than those which emerge from the type of work undertaken. For example: a business user may move to a position as a computer specialist and a computer specialist may move to a position in the user community. Similar barriers are experienced between the 'user' and systems developer when a computer specialist is the 'user' for a system being developed by another computer specialist as when developing systems for non-computing specialists. Even if 
initially the systems developer and the prospective user belonged to the same community, different roles imposed by the development can divide the community. We suggest that differences between business users and systems developers are cultural differences of values linked to cultural roles at level two of Wallerstein's (1990) abstraction, rather than personality differences at level three.

People are required to adopt a number of different roles during their daily life but cannot be definitively categorised as other species. Humans are not born computer specialists or business users or parents or salesmen, these are roles circumstances lead them to adopt. Rather than attributing differences in thinking to different types of people, it can be more adequately presented as differences resulting from adopted roles. Contemporary society is complicated as an individual can belong to different groups simultaneously, each of which uses its own linguistic and behavioural codes (Leach, 1965; Sengupta, 1977; Hofstede, 1991).

Recognition of one group's culture implies the coexistence of further cultures. Recognition of business users as a 'tribal unit', implies that the systems development community exists as a foreign tribe which is potentially in opposition. Cultural differences occur between the two communities when their behaviour is directed towards different goals (Tennekes, 1971).

\section{Cultural Analysis of Users and Systems Development Interaction}

User-systems developer interaction is often synonymous with conflict. Hofstede (1991) remarks that an external enemy has always been one of the most effective ways to maintain internal cohesion. This results from the basic belief in many cultures that what is different is dangerous. However, co-operation between rival tribes is sometimes necessary in order to address common problems (Hofstede, 1991). We suggest that cultural differences are at the foundation of conflict between users and systems development staff in an organisation.

The systems developer enters the tribe of users to analyse the business needs and information requirements. The role of the systems developer has been described as 'archaeologist and scribe' (Yourdon, 1989, p 56) whose purpose is to uncover details which may exist only as 'tribal folklore', passed down generations of users. Beynon-Davies (1990) suggests that there is similarity between the activities of the anthropologist investigating and documenting the life of a social group, and the activities undertaken to analyse information systems requirements. Table 2 summarises the tasks of the anthropologist identified by Nanda (1991), these tasks are also undertaken by an information systems developer.

\begin{tabular}{|l|}
\hline \multicolumn{1}{|c|}{ Tasks of an Anthropologist } \\
\hline Observe, learn and ask questions. \\
\hline Rely on informants for information and to establish a network of social relationships. \\
\hline Establish trust and co-operation in these relationships. \\
\hline Participate to understand the difference between what people say they do and the \\
action they actually take. \\
\hline Adopt the role of a stranger in another society.
\end{tabular}

Table 2: Tasks of an Anthropologist (based on Nanda, 1991)

The traditional approach to systems development adopts the ontological assumption that reality exists independently of any observer. Objectivity, observing behaviour without judgement, was also considered to be a necessary trait of the anthropologist (Tennekes, 1971). However, objectivity has been dismissed on the basis that as an anthropologist is a human being studying other human beings, a completely objective study of another culture is impossible (Robb, 1992; Nanda, 1991; Ackerman, 1965; Leach, 1965).

Anthropology aims to balance both an "insider's" view of a culture from a native point of view, with an external view of an "outsider". Both the systems developer and the anthropologist are required to balance participation to appreciate the natives' views with objectivity to perceive patterns and relationships of which a native may not be consciously aware (Nanda, 1991).

Objectivity may initiate further communication problems between tribes. Objectivity can be equated with remoteness which alienates both the researcher from his subjects and the subjects from the researcher. An objective detached approach may raise suspicion which further hinders effective communication. When entering a foreign community, it is the task of both the anthropologist and the systems developer to overcome the suspicion of a stranger. However, deliberate efforts to be accepted by the community can have an adverse effect. Strategies which exhibit overt friendliness, as presented by Joshi (1992) for example, can strengthen rather than diminish the walls of suspicion.

Suspicion between tribes needs to be transformed into trust. Rather than being a constructive approach, a stranger entering a community with the intention of obtaining an objective view of the situation may result in an adverse effect. The members of the community have developed a subjective view of their world and a stranger questioning that view is likely to be run out of town. This is because by challenging a person's view of the world, causes them 
to doubt the principles on which they have based their very existence. Zander (1977) suggests that members of an organisation may use secrecy to protect their culture and prevent the occurrence of undesirable conditions. A more conciliatory relationship may be developed by a more cautious approach which appreciates cultural differences.

Marcolin \& Higgins (1992) attribute communication problems between users and systems developers, to systems staff not being customer oriented. Systems developers provide a service to business departments and therefore business users are the clients of the systems department. A history of poor communication between the departments with the delivery of late and inadequate computer systems, has strengthened the barriers and tarnished opinions held by both communities.

Oliver \& Langford (1984) discuss common myths systems developers have concerning users which illustrate lack of respect to their clients. The myths include 'users keep changing their minds' (p 120), 'users are stupid' (p 122) and 'users react emotionally and illogically' ( $p$ 121). These myths reflect the lack of appreciation and understanding of systems developers to their client's situation.

The business environment encapsulates many dynamic forces of which the development of a computer system is just one component in the environment of the client. The systems analyst aims to obtain an objective view of the situation at a level of abstraction. The forces impacting the view of the analyst are relatively stable and changes to the business requirements may therefore seem illogical to the analyst. System developers need to appreciate the user's position in a dynamic environment.

Marcolin \& Higgins (1992) conclude that the development of a cooperative environment is essential for effective information systems development and can be achieved through mutual respect. The following section discusses the practical implications of applying cultural understanding to improve user-developer communication.

\section{PRACTICAL IMPLICATIONS OF CULTURAL UNDERSTANDING}

We have proposed that the difficulties experienced between users and systems developers are inherent to the cultural differences between the two social groups. We believe that an appreciation of these cultural differences can improve communication and interaction between the two groups. This view is supported by Hofstede (1991) who considers that negotiations are more likely to succeed if the parties understand the reasons behind their differing views. There is no defined procedure to achieve this level of understanding, however, we suggest key elements to improve all communication include:

1. Recognise that the community entered will have different cultural values.

2. Appreciate that the community comprises of individuals not stereotypes.

3. Develop a conducive context within which to work effectively with a different community. Guidelines for improving communication between users and information systems developers are presented in Shah et al. (1994). Hofstede (1991) suggests that there are three phases to the acquisition of intercultural communication abilities. These are:

1. Awareness: recognition that others have different mental software.

2. Knowledge: interaction with cultures, leads to knowledge (symbols, heroes and rituals) to understand where values differ.

3. Skills: recognition and application of symbols of other culture, experience satisfaction of getting along in the new environment, resolving simpler and more complicated problems of life among others.

Intercultural contact does not automatically breed mutual understanding, it only confirms each group has its own identity. Members of the other group are not perceived as individuals but as stereotypes. Wynn (1982, p 349) argues that while user are represented 'two-dimensionally, stereotypically, adversarially' user participation in systems design will be restricted.

\section{Cultural Appreciation in Systems Development}

Figure 2 summarises recommendations to improve communication in information systems development.

\section{Explain Terminology}

All departments must recognise that the language they use may not be understood outside the confines of their specialist area. The manipulation of language to reinforce departmental barriers hinders effective communication. There is no standard for considering one group as inferior or superior to another (Hofstede, 1991). A business user who does not share the same specialism as a systems developer, is no less inferior to the developer, than the systems developer is to the business specialist for whom the system is being developed. Careful use of specialist terminology portrays greater professionalism than irresponsible administration of jargon. 


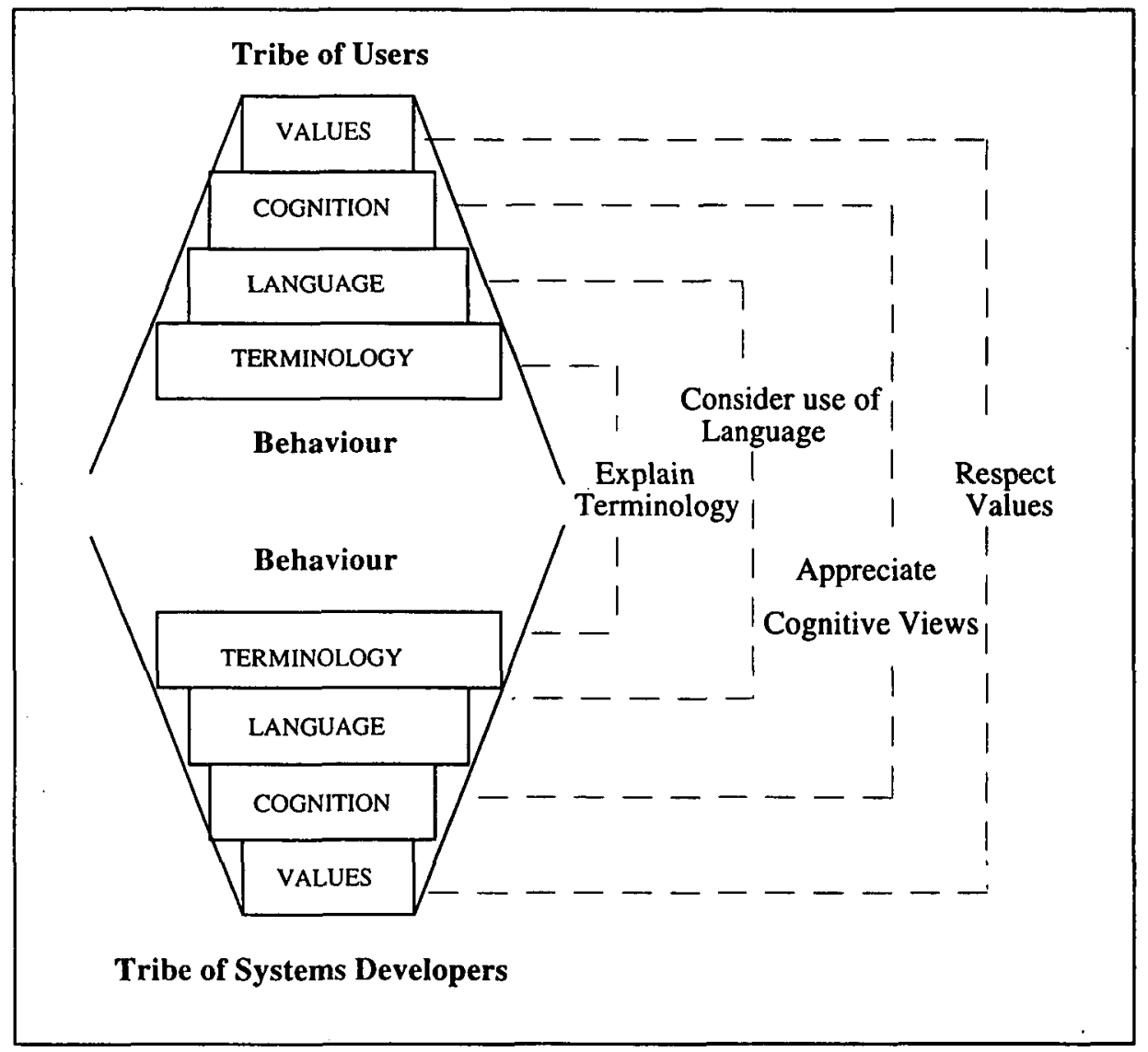

Figure 2: Improving Communication in Information Systems Development

\section{Consider Use of Language}

The development of effective and efficient information systems requires the resolution of communication problems experienced between users and systems developers (Christensen, 1991). Language is the resource of communication but it is ambiguous; misunderstandings occur within, among and between groups (Valusek \& Fryback, 1985). As Shekelton (1991) suggested, both clients and systems developer need to be cautious and consider the use of language from a different perspective.

\section{Appreciate Different Cognitive Views}

In addition to possessing, universal characteristics and the characteristics of a particular group, a person also possesses idiosyncratic characteristics (Wallerstein, 1990). This combination of characteristics constructs a unique individual with a different, valid view of the world. It is therefore necessary to be aware that different frames of reference exist.

\section{Respect Values}

An individual is a member of many groups each of which has a different culture and within each group, the individual adopts particular roles. In the user-systems developer relationship, the individuals involved adopt specific roles which represent their values. An appreciation of the different roles in a relationship is necessary to improve communication and interaction.

\section{Summary of Approach}

The approach of cultural appreciation advocated in this paper is summarised by Segall et al. (1990, p 316) who propose that 'to avoid impending ecological catastrophes.... we ought to identify with the whole human race as enthusiastically as we presently do with our own tribes'. Although lack of cultural appreciation will not result in 'ecological catastrophe', the results may prove just as catastrophic to the organisation concerned. 


\section{CONCLUSION}

Information systems development requires effective interaction between systems development and other departments. We suggest basic cultural differences are the origin of both the cause and resolution of interdepartmental communication problems.

Organisations, functions, departments and offices form specialisations which exhibit distinct 'sub-cultures' in the anthropological sense (Bell, 1979). A cultural system emerges within a department which may be distinct from that of a neighbouring department or the corporate culture. Communication barriers are erected between these communities to retain and protect individual departmental cultures. Cultural systems are a necessary part of human activity, fulfilling the human need to identify with a social group, dictating how an individual perceives their environment which is manifested in, for example, their use of language. 'Outsiders' to the culture are treated with suspicion and 'insiders' unite to defend their community against the perceived threat of attack. We suggest that both effective interdepartmental and international communication cannot be achieved by attempting to change, persuade or convert the other tribe but through the appreciation and understanding of different cultures.

\section{REFERENCES}

Ackerman, J.S. (1965) “On Scientia”, in: Halton, G. (ed.), Science and Culture: A Study of Cohesive and Disjunctive Forces, Boston: Beacon Press, pp 14-23.Anderson, J.M. (1993) "Jargon Convergence as a Measure of Alignment in Understanding Between Management and Information Systems Professionals", IBS Computing Quarterly, Winter, pp 8-15.Avison, D.E., Shah, H.U., Powell, R.S. \& Uppal, P.S. (1992) "Applying Methodologies for Information Systems Development", Journal of Information Technology, Vol 7 No 3, pp 127-140.Barkema, H., Bell, J. \& Pennings, J. (1996) "Foreign Entry, Cultural Barriers and Learning", Strategic Management Journal, Vol 17, pp 151-166.Baroudi, J.J., Olson, M.H. \& Ives, B. (1986) “An Empirical Study of the Impact of User Involvement on Systems Usage and Information Satisfaction", Communications of the ACM, Vol 29 No 3, pp 232-238.Becher, T. (1989) Academic Tribes and Territories: Intellectual Enquiry and the Cultures of Disciplines, Milton Keynes: Open University Press.

Bell, D. (1979) "The Disjunction of Culture and Social Structure: Some Notes on the Meaning of Social Reality", in: Barret, M., Corrigan, P., Kuhn, A. \& Wolff, J. (eds.), Ideology and Cultural Production, Great Britain: Croom Helm Ltd, pp 236-250.Benbasat, I., Dexter, A.S. \& Mantha, R.W. (1980) "Impact of Organisational Maturity on Information System Skill Needs", MIS Quarterly, Vol 4 No 1, pp 21-34.

Berger, M. (1996) Cross-Cultural Team Building: Guidelines for More Effective Communication and Negotiation, Maidenhead: McGraw-Hill.

Beynon-Davies, P. (1990) "The Behaviour of Systems Analysts", Computer Bulletin, March, pp 21-23.

Bird, E. (1979) "Aesthetic Neutrality and the Sociology of Art", in: Barret, M., Corrigan, P., Kuhn, A. \& Wolff, J. (eds.), Ideology and Cultural Production, Great Britain: Croom Helm Ltd, pp 25-48,.

Bostrom, R.P. (1989) "Successful Application of Communication Techniques to Improve the Systems Development Process", Information and Management, Vol 16 No 5, pp 279-295.

Cavaye, A.L.M. \& Christiansen, J.K. (1996) "Understanding IS Implementation by Estimating Power of Subunits", European Journal of Information Systems, Vol 5 No 4, pp 222-232.

Christensen, D.M. (1991) "The Gap Between Systems Developers and Users", Information Systems Management, Vol 8 No 4, pp 73-75.

Crockett, H.D., Guynes, J. \& Slinkman, C.W. (1991) "Framework for Development of Conceptual Data Modelling Techniques", Information and Software Technology, Vol 22 No 2, pp 134-141.

Cronan, T.P. \& Means, T.L. (1984) "Systems Development: An Empirical Study of User Communication", DataBase, Vol 15 No 3, pp 25-33.

Denison, D.R., Hart, S.L. \& Kahn, J.A. (1996) "From Chimneys to Cross-Functional Teams: Developing and Validating a Diagnostic Model", Academy of Management Journal, Vol 39 No 4, pp 005-1023.

Dingley, S. (1996) "A Composite Framework for the Strategic Alignment of Information Systems Development", Phd Thesis, Department of Computer Science and Applied Mathematics, Aston University in Birmingham, UK.

Ferratt, T.W. \& Short, L.E. (1988) "Are Information Systems People Different? An Investigation of How They Are and Should Be Managed", MIS Quarterly, Vol 12 No 3, pp 427-443.

Gingras, L. \& Mclean, R.L. (1982) "Designers and Users of Information Systems: A Study of Differing Profiles", Proceedings of the 3rd International Conference on Information Systems, Ann Arbor, Michigan, pp 169181.

Guinan, P.J. \& Bostrom, R.P. (1986) “Development of Computer-Based Information Systems: A Communications Framework", Data Base, Vol 17 No 3, pp 3-16.

Hirschheim, R. \& Newman, M. (1988) "Information Systems and User Resistance: Theory and Practice", The Computer Journal, Vol 31 No 5, pp 398-408.

Hofstede, G. (1991) Cultures and Organisations: Software of the Mind: Intercultural Cooperation and its Importance for Survival, Maidenhead: McGraw-Hill. 
Hofstede, G. (1998) "Identifying Organizational Subcultures: An Empirical Approach", Journal of Management Studies, Vol 35 No 1, pp 1-12.

Hunter, M.G. \& Beck, J.E. (1996) "A Cross-Cultural Comparison of "Excellent" Systems Analysts", Information Systems Journal, Vol 6 No 4, pp 261-281.

Johnson, G. (1992) "Managing Strategic Change - Strategy, Culture and Action", Long Range Planning, Vol 25 No 1, pp 28-36.

Johnson, R. (1979) "Histories of Culture / Theories of Ideology: Notes of an Impasse", in: Barret, M., Corrigan, P., Kuhn, A. \& Wolff, J. (eds.), Ideology and Cultural Production, Great Britain: Croom Helm Ltd., pp 49-77.

Joshi, K. (1992) "Interpersonal Skills for Cooperative User-Analyst Relationships: Some Research Issues”, Data Base, Vol 23 No 1, pp 23-25.

Kaiser, K.M. \& Bostrom, R.P. (1982) "Personality Characteristics of MIS Project Teams: An Empirical Study and Action-Research Design”, MIS Quarterly, Vol 6 No 4, pp 43-60.

Kaiser, K.M. \& King, W.R. (1982) “The Manager Analyst Interface in Systems Development", MIS Quarterly, Vol 6 No 1, pp 49-59.

Kaulio, M.A. \& Karlsson, M. (1998) "Triangulation Strategies in User Requirements Investigations: a Case Study on the Development of an IT-Mediated Service", Behaviour and Information Technology, Vol 17 No 2, pp 103-112.

Kumar, K. \& Welke, R.J. (1984) “Implementation Failure and System Developer Values: Assumption, Truisms, and Empirical Evidence”, Proceedings of the ICIS Conference, Tuscon, Arizona, pp 1-17.

Leach, E.R. (1965) "Culture and Social Cohesion", in: Halton, G., (ed.), Science and Culture: A Study of Cohesive and Disjunctive Forces, Boston : Beacon Press, pp 24-38.

Leach, E. (1976) Culture and Communication: The Logic by which Symbols are Connected: An Introduction to the Use of Structuralist Analysis in Social Anthropology, Cambridge: Cambridge University Press.

Levin, H. (1965) "Semantics of Culture", in: Halton, G., (ed.), Science and Culture: A Study of Cohesive and Disjunctive Forces, Beacon Press, Boston, pp 1-13.

Lucas, H.C. Jr. (1984) "Organisational Power and the Information Services Department", Communications of the ACM, Vol 27 No 1, pp 58-65.

Marcolin, B.L. \& Higgins, C.A. (1992) “Effectively Dealing with IS User Complaints”, Journal of Systems Management, Vol 44 No 12, pp 29-36.

Markarian, E.S. (1977) "The Concept of Culture in the System of Modern Science", in: Bernadi, B. (ed.), The Concepts and Dynamics of Culture, Netherlands: Mouton Publisher, pp 103-118.

Markus, M.L. \& Bjorn-Anderson, N. (1987) "Power Over Users: Its Exercise by Systems Professionals", Communications of the ACM, Vol 30 No 6, pp 498-504.

Martin, M.P. \& Fuerst, W.L. (1984) "Communications Framework for Systems Design”, Journal of Systems Management, Vol 35 No 3, pp 18-25.

Meyer, H-D. (1993) "The Cultural Gap in Long-Term International Work Groups: A German-American Case Study", European Management Journal, Vol 11 No 1, pp 93-101.

Mittermeir, R.T., Hsia, P. \& Yeh, R.T. (1982) "Alternatives to Overcome Communication Problem of Formal Requirements Analysis", in: Galliers, R. (Ed.), Information Analysis - Selected Readings, Wokingham: Addison-Wesley, pp 153-165.

Nanda, S. (1991) Cultural Anthropology, Belmont: Wadsworth Publishing Company.

Oliver, I. \& Hall, A. (1984) "A Repertory Grid Study of the Systems Analyst - Client Interface", International Journal of Man-Machine Studies.

Oliver, I. \& Langford, H. (1984) "Myths of Demons and Users: Evidence and Analysis of Negative Perceptions of Users”, Galliers, R. (Ed.), Information Analysis - Selected Readings, Wokingham: Addison-Wesley, pp 113123.

Park, S.H. \& Ungson, G. R. (1997) "The Effect of National Culture, Organizational Complementarity, and Economic Motivation on Joint Venture Dissolution", Academy of Management Journal, Vol 40 No 2, pp 279-307.

Parkinson, R.N. (1993) "International Group Working”, Internal Report, Department of Computer Science and Applied Mathematics, Aston University in Birmingham, UK.

Robb, F.R. (1992) “Organisations, Institutions and Management”, Systemist, Vol 14 No 1 pp 15-25.

Robey, D. \& Farrow, D. (1982) "User Involvement in Information Systems Development: A Conflict Model and Empirical Test”, Management Science, Vol 28 No 1, pp 73-85.

Rourke, G. \& Elliot, G. (1996) "Strategic Management of the Culture Gap”, Proceedings of the BIT'96 Conference, Business Information Systems - Uncertain Future, Vol 2, Manchester Metropolitan University, Manchester, UK, pp 209-219.

Saunders, C.S. \& Scamell, R.W. (1986) "Organisational Power and the Information Services Department: A Reexamination", Communications of the ACM, Vol 29 No 2, pp 142-147.

Segall, M.H., Dasen, P.R., Berry, J.W. \& Poortinga, Y.H. (1990) Human Behaviour in Global Perspective: An Introduction to Cross-Cultural Psychology, Oxford: Pergamon Press. 
Sengupta, D. (1977) “A Unified Theory of Society - Field Aspect”, in: Bernadi, B. (Ed.), The Concepts and Dynamics of Culture, Netherlands: Mouton Publisher, pp 119-140.

Shah, H.U., Dingley, S. \& Golder, P. (1994) "Bridging the Culture Gap Between Users and Developers", Journal of Systems Management, Vol 45 No 7, pp 18-21.

Shekelton, J.F. (1991) "Aristotle, The Entity Model and Neurosis", Boxes and Arrows, Vol 92, pp 11-14.

Smith, A.D. (1990) "Towards a Global Culture?", Theory, Culture and Society, Vol 7 No 2-3, pp 171-191.

Taggart, Jr. W.M. (1982) "The Other Half of the Systems Development Potential: Are We Half-brained Systems Professionals?", Computer Personnel, Vol 9 No 1, pp 17-22.

Tan, W-G. \& Gable, G.G. (1997) "Maintaining Centralised Application Systems: a Cross-Country, Cross-Sector, Cross-Platform Comparison”, European Journal of Information Systems, Vol 6 No 4, pp 193-207.

Tennekes, J. (1971) Anthropology Relativism and Method: An Inquiry into the Methodological Principles of a Science of Culture, Netherlands: Van Gorcum and Company.

Valusek, J.R. \& Fryback, D.G. (1985) "Information Requirements: Obstacles Within, Among and Between Participants”, in: Galliers, R. (Ed.), Information Analysis - Selected Readings, Wokingham: Addison-Wesley, pp 139-151.

Wallerstein, I. (1990) "Culture as the Ideological Battleground of the Modern World-System", Theory, Culture and Society, Vol 7 No 2-3, pp 31-55.

Walmsley, J. (1986) Brit-Think Ameri-Think: A Transatlantic Survival Guide, London: Harrap Books.

Weinberg, G.M. (1971) The Psychology of Computer Programming, . Van New York: Nostrand Reinhold.

Werner, R. (1979) “The Business Systems Professional”, MIS Quarterly, Vol 3 No 1, pp 65-66.

Wynn, E.H. (1982) "The User as a Representation Issue in the US", Systems Design For, With, and By, the Users, Proceedings of the IFIP WG 9.1 Working Conference on Systems Design For, With, and By the Users (Briefs U, Ciborra C and Schneider L, Eds), Netherlands: North-Holland Publishing Company, pp 349-358.

Yourdon, E. (1989) Modern Structured Analysis, New York: Prentice Hall.

Zander, A. (1977) Groups at Work, United States of America: Jossey-Bass Publishers. 